\title{
On the infiltration of sports spirit in university campus
}

\author{
Linbao Zhang \\ P.E Department, Shangrao Normal University, Shangrao, 334000, China.
}

3235777167@qq.com

Keywords: university students, Quality education, sports spirit.

\begin{abstract}
College students are the initiators and promoters of the trend of thought. The infiltration of sports spirit on university campus can help the social communication of sports spirit, and it More can manifest the university campus quality education diversity. Through literature, observation, logic analysis and other methods, this paper explores the connotation of sports spirit, the connotation of sports spirit in university campus and the strategy of sports spirit infiltration in university campus. The purpose is to serve the sports spirit in university campus.
\end{abstract}

\section{Introduction}

Alto, Spain's famous thinkers in the 20th century, and think: establish meet the requirements of The Times in college ideological system, sets up the lofty spiritual realm, is one of the university of above the other, the basic function of university should first put the educatees training to become a man with "the spirit of the people", making them at times the height of the standard required, the essence and soul of spirit of university existence and development.

The university campus not only let students feel the existence of material conditions, but also should strengthen the dissemination and edification of culture and spirit. The spiritual consciousness is the foundation of the development of the university, which is the foundation for the development of students' emotional intelligence and the social survival. As an important part of campus spirit, sports spirit plays an irreplaceable role in the growth of college students.

\section{The connotation of sports spirit.}

Thought from the perspective of marxist philosophy, the spirit, refers to the "with material contrast, consistent and consciousness of philosophical category, is human consciousness, thinking activity and the floorboard of the general state of mind." Join at sports from different nationalities, different countries in the world can create and infinite wisdom, assemble the great human life force, the inexhaustible creative potential and clever clever. The sportsmanship shown in sports is the highest product of sport, the soul and essence of sports. The spirit of sports reflects the pursuit of human values and is a vivid reflection of the outstanding character and lofty ideals of human beings. It is the precious spiritual wealth of human society.

Sports spirit is often closely related to the progress of social civilization. From western countries freedom and equality, fair competition, pursuit of excellence in major sports spirit, the Olympic movement is higher, faster, stronger sports maxim, and Chinese women's volleyball team's selfless dedication, unity, cooperation, hard work, unyielding spirit and sports stars benevolence benevolence all interpretation of sports spirit in the process of human civilization, at the same time challenge the spirit and the progress of social civilization. The definition of sports spirit has many experts give reasonable and scientific explanation. According to the analysis, the sports spirit should be refracted from two aspects, one is the connotation itself, but the event behavior itself. Human connotation is the implicit behavior formed by the reflection of human brain, which is a "latent expression" of consciousness. And the event behavior itself is a kind of performance in the field, sports activities and other behaviors, is an explicit behavior. The two have mutual influence, infiltration and interaction. The spirit of college physical education can be considered from three aspects, namely, the concept of physical education, the professional quality of PE teachers and the 
pursuit of career, the concept and quality of students' sports. It covers the sports teaching management department, the physical education teacher, the student three groups. The spirit of sportsmanship is not only the spirit of striving, advancing and winning, but also the spirit of solidarity and cooperation, equality and fraternity, mutual respect and mutual benefit.

\section{The significance of sports spirit infiltration in university campus.}

\subsection{It can fully reflect the promotion of education in education system of the school.}

Quality education is the embodiment of the comprehensive quality education, virtue leads, ability is heavy, comprehensive development. The sports spirit infiltration in university physical education embodies the goal setting of diversified teaching in physical education, which can help the all-round development of social construction talents.

The spirit of sports can make college students to develop high moral standards and realistic and practical style. The sports career contains the spirit of "rule consciousness", "fair competition", "solidarity and cooperation", "victory is not pride and defeat". These spirits move over time to the daily life of University students and thus affect their development.

\subsection{Contribute to the construction of harmonious campus.}

University campus is an environment of material environment and social environment, and environmental construction is of great significance to the harmonious development of campus. Sports mental environment is an important part of social environment. The construction of sports spirit environment is an invisible driving force, which can guide the development of good school spirit in the campus, form the right healthy thought essence, and help build the harmonious campus.

\subsection{Contribute to the healthy growth of university students.}

Sports spirit is the "soul" that promotes the healthy growth of university students, and leads and drives the correct direction for university students. Mr. CAI yuanpei believes that "the construction of sports spiritual civilization is very important for human's healthy personality construction". The current understanding of health generally inclines to the four dimensions of "physical health, mental health, moral health and social adaptation". According to the connotation of sports spirit, it can be believed that education is very important to promote the healthy development of university students.

\subsection{It is conducive to the development of social spiritual civilization.}

Sports spirit is an important part of social spiritual civilization. Attaches great importance to the spirit of sports teaching in university sports teaching, to promote university students' positive attitude toward behavior and maintain the correct moral bottom line, the matters and distinguish between right and wrong, and for moves towards social work to lay the foundation. As university students are the new force of society, the degree of sports spirit will directly or indirectly promote the development of social spiritual civilization construction.

\subsection{Is an important component of healthy China construction.}

In October 2016, China released the outline of the healthy China 2030 plan, and the healthy China has been implemented in the sports arena. President xi jinping stressed that "to accelerate the construction of a strong sports country, we should carry forward the spirit of Chinese sports". Carry forward the spirit of sports in university physical education teaching, students' sports power connotation construction, not only can let the students to be able to understand the true meaning of the sports value, the more will be able to make the spread this truth in the society, the development of the national fitness system construction is of great significance and the construction, and promote the construction of health in China. 


\section{Sports spirit infiltration strategy in university campus.}

\subsection{Promote sports spirit through the cloud service platform.}

With the help of the campus local area network (LAN) to establish the university sports teaching cloud services platform, sport propaganda module, which set up the thought of sports in China, the Olympic culture, sports stars, sports team, etc. To collect, as university students the content of the reading after class.

\subsection{Build the school sports spirit and cultural environment.}

The school sports spirit culture environment is the comprehensive spiritual culture atmosphere which formed during the long running process to the cognition, emotion and behavior of sports activities. It covers the school sports tradition, the school sports morality, the school sports atmosphere, the school sports thought and so on. A large number of studies have shown that people's attitudes tend to be generalized, and the surrounding atmosphere and behavior will influence the individual's thinking and actions. Therefore, a good cultural environment of school sports will exert a subtle influence on students' spirit.

\subsection{Integrate sports spirit education into classroom routine.}

The experience of physical education has an indelible mark on every university student. Therefore, the experience in PE class has great influence on students. Therefore, it is necessary to strengthen the sports spirit education in PE class. However, in the current college physical education class, most of the time and energy are put on education, which tends to ignore the education of sports spirit. Therefore, the students' perception of the sports spirit is less and less, which often leads to the lack of good qualities such as perseverance, confidence and determination, as well as the occurrence of major problems in personality. Only when the spirit of sports can be effectively injected into the students' study, will there be a more harmonious and healthy social civilization construction. Therefore, it is necessary to integrate the sports spirit into the teaching routine of physical education, so that students can understand the spirit of sportsmanship on a daily basis.

\subsection{To create conditions to observe the local and international competitions and expand the channels of sports spirit transmission.}

Psychological research shows that $80 \%$ of the information you experience can be remembered. One of the most important means of sportsmanship is to experience it in person. Nowadays, colleges and universities are located in different areas, and there are more and more competitions in different forms of domestic and international competitions. , therefore, to take this opportunity to expand college students' sports class, create conditions for the university sports classroom teaching with the game view organically, improve college students' comprehension of sports connotation, enhance the sports spirit of understanding and perception.

4.5 University campuses have established such groups as "sports home", which regularly discuss sports spirit issues and promote the sports spirit awareness of university students.

The university is the academic hall, the university students have the foresight and the solid academic research foundation. Set up groups, such as "home of sports", analyzes all kinds of sports events in the sports spirit to explore, combing the spirit category, spread to university students for the center with community sports spirit essence.

\subsection{University campus focuses on sports humanistic spirit transmission.}

The extension of humanistic spirit is extensive, including consciousness, concept, attitude, proposition, purpose, etc. It emphasizes the value judgment and pursuit of value. In the university campus sports humanistic spirit spread in the process of shaping behavior person of humanistic spirit, guide the correct outlook on life, values, world view development, contribute to the formation 
of comprehensive sports spirit, is conducive to the realization of the dream world power.

\subsection{Establish the university students' sports spirit evaluation system.}

In order to better cultivate college students' sportsmanship from tube, can we regularly organize the correct sports knowledge and carries forward the sports spirit of sports, at the same time, to the evaluation results of sportsmanship as a part of the university sports curriculum evaluation. To maintain the spirit of sportsmanship.

\section{Summary}

Xiaoming Hu believes that sports spirit is a universal value of sports culture. Then it will bring about the development of the connotation of college students. Our IQ, dynamic, eq human complex complex, can grab sports spirit essence, the essence of the three development provides the positive energy for better development of human society, also to help college students set up social survival faith.

Shape healthy under the background of China's university sports spirit has the practical significance, can fully embody health health groups and connotation of the content of China, at the same time can contribute to spread positive energy to expand sports audience. It will also provide important support for the transformation of sports powers to sports power.

\section{References}

[1] Kehong Yu, Qiao. Zhang On sports spirit and university spirit [J]. Journal of physical education, 2014,21 (3): 80-83.

[2] Xiaohui Wang, Guihai Liu. Sports spirit: analysis based on linguistic philosophy [J]. Journal of Shanghai institute of physical education, 2011, 41 (1): 7-12.

[3] Fanqiang Zeng, Weihua Chen. The cultivation of sports spirit [J]. Journal of hunan university of science and technology, 2006,27 (5): 210-212.

[4] Hu Hu. The inheritance of sports culture and Olympic spirit on university campus [J]. Zhejiang sports science, 2007,29 (3): 65-67.

[5] Chuang Liu. The way of university: the inheritance, production and originality of spirit [J]. Modern university education,2003,9(6): 22-25.

[6] Li Huang. Cultural connotation and value construction of sports spirit [J]. Sports science,2007,27(6): 88-95.

[7] Chunhui Li. The connotation, characteristics and construction of sports culture in contemporary China [J]. Journal of Beijing sports university, 2015,38 (12): 22-26. 